\title{
Young children's part-whole acquisition and transfer of knowledge of a fact matrix on cats
}

\author{
JILL SCHANBACHER, CAROL MARTIN-DAVIDSON, ALBERT GOSS, \\ and BERNARD DAVIDSON \\ Rutgers College, Douglass College, and the Graduate School of Education, Rutgers University \\ New Brunswick, New Jersey 08903
}

\begin{abstract}
A color photograph of an exemplar of each of six breeds of domestic cat was shown to young children. Correct verbalizations of values of the exemplars' coat color (CCs), coat length (CLs), and eye colors (ECs) were fist assessed and then, with breed names, strengthened through four study-test trials under part (P), cumulative part (CP), or whole (W) presentation, and through four more study-test trials under common $W$ presentation. By the last studytest trial, breed names and verbalization of $\mathrm{CC}, \mathrm{Cl}$, and $\mathrm{EC}$ had increased. When the photographs were replaced by spoken breed names, correct verbalizations of $\mathrm{CC}, \mathrm{EC}$, and CL decreased precipitously to lower percentages of occurrence. Initial P, CP, or W presentation made essentially no difference in acquisition of breed names, in strengthening verbalizations of values of attributes of CC, CL, and EC, or in transfer of verbalizations of values from photographs to breed names.
\end{abstract}

Young children's initial knowledge and subsequent increases in knowledge of fact, "meaning," or semantic matrices is essentially unexplored. In a fact matrix, one or more attributes, dimensions, features, or "vectors" are constituted of a sample of names for or representations of members of subclasses of a class of objects, of persons or things. Additional attributes are specified and then constituted of particular values of physical or of anatomical, physiological, behavioral and, perhaps, other kinds of attributes.

Fact matrices are often realized in a tabular format whose leftmost columns consist of or allow for representations (e.g., color photographs) and names of each of several subclasses of a class of objects, for example, the 15 breeds of domestic cats shown in Table 1. Additional columns are headed by appropriate general names for qualitative or quantitative attributes, in this case, coat color (CC), coat length (CL), and eye color (EC). Cells of each column may be completely or partially, appropriately or inappropriately filled with particular values of each attribute.

Goss (1971) and Musgrave and Cohen (1971) show how elements and relationships of fact matrices can be decomposed into or constructed from lists such as paired associates (PA) in $1: 1, n: 1,1: n$, or $n: n$ patterns of pairings or relationships either alone or superimposed. They also show how fact matrices may be embedded in prose or discourse.

Within this perspective, all of the classes of variables of PA learning (Goss, 1971; Goss \& Nodine, 1965)

Requests for reprints should be sent to Albert E. Goss, Department of Psychology, Douglass College, Rutgers University, New Brunswick, New Jersey 08903. The authors were helped by Carol Merce, Director of the REM County Day School in East Brunswick, New Jersey, the children who participated, and these children's parents. are potentially pertinent to acquisition, transfer, and retention of fact matrices. Among the many classes of variables of PA learning that might be extended to the learning of fact matrices, the choice here was the partwhole manipulation: It is a ubiquitous class of variables within and across tasks, and parents and teachers are likely to introduce these variations, albeit unsystematically.

With a particular fact matrix, each "part" may be some subset of rows, some subset of columns, or both. The part-whole manipulation here was to divide by rows. This corresponds more closely to the part-whole manipulation of a conventional PA list. Following Postman and Goggin (1966, Experiment 2), this manipulation involved initial part $(\mathrm{P})$, repetitive or cumulative part (CP), or whole $(\mathrm{W})$ presentation.

Table 1

Sample of Breeds and Remaining Breeds with Values of $\mathrm{CC}, \mathrm{CL}$, and EC and Source Page of Each Photograph (Warner, 1976)

\begin{tabular}{|c|c|c|c|c|}
\hline Breed Name & $\mathrm{CC}$ & CL & EC & Page \\
\hline \multicolumn{5}{|c|}{ Sample List of Six Breeds } \\
\hline Abyssinian & gray, white, brown & short & yellow & 43 \\
\hline Birman & light brown, dark brown & long & blue & 46 \\
\hline Calico & black, orange, white & long & orange & 96 \\
\hline Chinchilla & white & long & green & 59 \\
\hline Korat & blue & short & yellow & 67 \\
\hline Manx & white, brown & short & green & 70 \\
\hline \multicolumn{5}{|c|}{ Remaining Breeds } \\
\hline Balinese & light brown, dark brown & long & blue & 44 \\
\hline Burmese & brown & short & blue & 55 \\
\hline Cameo Persian & white & long & gold & 101 \\
\hline Cornish Rex & sandy & short & yellow & 73 \\
\hline Havana & dark brown & short & green & 69 \\
\hline Himalayan & white, dark brown & long & blue & 65 \\
\hline Maine Coon & white, brown, black & long & green & 69 \\
\hline Siamese & black, brown & short & blue & 77 \\
\hline Sphinx & yellow, gray & short & yellow & 86 \\
\hline
\end{tabular}




\section{METHOD}

\section{Subjects}

Female (18) and male (18) 4- and 5-year-olds (mean $=57$ months, range $=51-63$ months) from a private, suburban nursery school were assigned randomly in equal numbers to initial $P$, $\mathrm{CP}$, or $\mathrm{W}$ presentation. Typically of middle and upper-middle SES, all but three of the children were white. The exceptions were a Japanese male, an Indian male, and a black female.

\section{Stimuli}

Warner (1976) was the source of a color photograph of an examplar of each of 15 breeds of domestic cat. These breeds were about equally shorthair and longhair; none of their names included the value of a specific color. The six rows at the top of Table 1 illustrate the different matrices of breed names and values of $C C, C L$, and $E C$ that, along with photographs of the breeds, served as stimuli for each child. A matrix for each child was selected randomly from among all 15 rows within the constraint of three each of shorthair and longhair breeds.

The photographs for assessment of initial verbalizations and for the study phase of trials were against monochromatic backgrounds. The test phase of these trials was with parallel photographs, with no background. All photographs were laminated in clear plastic.

\section{Procedure}

Initial verbalizations. The photographs of each of the six breeds of a list were shown once in a random order to obtain answers to "What color is its fur?" "Is its fur long or short?", and, when an eye or eyes could be seen, "What color is (are) its eye (eyes)?" Responses were simply recorded.

Time of presentation was paced to allow full opportunity for a child to answer each question. Total time for all six photographs averaged about $5 \mathrm{~min}$.

Acquisition: P, CP, or W. One or more days after assessment of initial verbalizations, each child was brought back for four study-test trials under $\mathrm{P}, \mathrm{CP}$, or $\mathrm{W}$ presentation of photographs of the selected breeds for which breed names and values of $\mathrm{CC}$, $\mathrm{CL}$, and EC of each breed were the experimenter-supplied stimuli for responses. For the nine females and nine males run by each of two female experimenters, assignment to $\mathrm{P}, \mathrm{CP}$, or W presentation was random. Occurrence of these presentations was counterbalanced.

Under $P$ presentation, a child was to learn the names of and the values of the CC, CL, and EC of both members of each of three pairs of photographs. Each pair had one shorthair and one longhair breed.

Each trial began with a study phase: The child looked at the photograph of one breed of a pair and was told its name, CC, $\mathrm{CL}$, and EC. These were repeated by the child. The same procedure was followed with the photograph of the other breed of a pair.

Each trial ended with a test phase: the child looked at the photograph of one breed of a pair and replied to successive questions of its name, CC, CL, and EC. This was repeated with the photograph of the other breed.

After four trials or attainment of a criterion of perfect responses to both photographs, the photographs of the second pair and then those of the third pair were presented for acquisition in the same way. Four trials with each of the three pairs took 20-25 $\mathrm{min}$.

Under CP presentation, the procedure with the first of three pairs of photographs paralleled that of $P$ presentation. Then, instead of replacing the first pair of photographs, the second pair was added to make a sublist of four photographs.

A complete session first with one pair and then with both pairs also took 20-25 min. Children of this condition had as many trials with photographs of the cats for as much time as children of the $\mathbf{P}$ condition, with double exposure to one pair rather than exposure to a third pair.

Under $W$ presentation, each child had four study-test trials with all six photographs of a list. Or, the session ended with attainment of a criterion of perfect responses to all six. These four trials also took $20-25 \mathrm{~min}$.

Acquisition: All W. Within 3 days after acquisition under $P$, $\mathrm{CP}$, or $\mathrm{W}$ presentation, a child was brought back for further acquisition under only $\mathrm{W}$ presentation of all six photographs of a list. There were four trials, or termination with perfect responses to all six photographs. Again, a session of four trials took 20-25 $\mathrm{min}$.

Transfer: W. For the last session, photographs were no longer shown. Instead, breed names became the stimuli, and values of $\mathrm{CC}, \mathrm{CL}$, and EC became the responses to be transferred to breed names for further strengthening of their relationships to breed names and, perhaps, to each other.

The first trial had only a test phase: A child was told successively the six breed names of a subset and asked the CC, CL, and EC for each breed. During the study phase of two additional trials, the child was told the breed name and then its CC, CL, and EC. This session took 10-15 $\mathrm{min}$.

\section{RESULTS}

\section{Initial Verbalizations}

The children were not asked to name particular breeds initially. Preliminary exploration had shown that other children of the same age could not do so. The top three rows of Table 2 show the percentages of correct CC, CL, and EC verbalizations by females and males combined who were to be under $\mathrm{P}, \mathrm{CP}$, or $\mathrm{W}$ presentation. Verbalizations of CC or EC were considered correct only if they were the same as or close synonyms of values in Table 1. Correct CL responses were appropriate verbalization of "long" or "short." Because of differences among CC, CL, and EC in size of response classes, these measures are not equivalent.

In the ANOVAS for correct CC, CL, and EC responses, none of the Fs for subsequent $\mathrm{P}, \mathrm{CP}$, or $\mathrm{W}$ presentation was at $p<.05$. Nor were any of the Fs for interactions of presentation with sex of the child (gender) or experimenter at $p<.05$. More correct $C C$ responses occurred with one than with the other experimenter

Table 2

Means of Percentages of Correct Name (N), CC, CL, and EC Responses for Initial Verbalizations, Acquisition, and Transfer

\begin{tabular}{llrrrr}
\hline Task or Phenomenon & Condition & N & CC & CL & EC \\
\hline & P & & 32 & 72 & 22 \\
Initial Verbalizations & CP & & 19 & 51 & 25 \\
& W & & 29 & 60 & 36 \\
Acquisition: P, CP, or W & P & 24 & 59 & 88 & 86 \\
& CP & 17 & 48 & 81 & 75 \\
& W & 7 & 48 & 75 & 72 \\
Acquisition: W & P & 16 & 63 & 87 & 85 \\
& CP & 26 & 47 & 86 & 75 \\
& W & 22 & 62 & 82 & 82 \\
Transfer: W & P & & 15 & 42 & 31 \\
& CP & & 18 & 59 & 27 \\
& W & & 20 & 62 & 37 \\
\hline
\end{tabular}


$[F(1,24)=4.74, p<.05]$. Gender made no difference. Across $\mathrm{P}, \mathrm{CP}$, or $\mathrm{W}$ presentation, about $27 \%$ of the verbalizations of $\mathrm{CC}, 28 \%$ of those of $\mathrm{EC}$, and $61 \%$ of those of $\mathrm{CL}$ were correct.

\section{Acquisition: $\mathbf{P}, \mathrm{CP}$, or $\mathrm{W}$}

Table 2 also shows the percentages of correct names and of verbalizations of $\mathrm{CC}, \mathrm{CL}$, and $\mathrm{EC}$ across trials under $\mathrm{P}, \mathrm{CP}$, or $\mathrm{W}$ presentation. The percentages for $P$ presentation are across each of the three pairs that were presented successively; those for $\mathrm{W}$ presentation are for all six pairs through all four trials.

The percentages of correct verbalizations under $\mathrm{CP}$ presentation are complex in origin. One component is correct verbalizations for the first pair during trials with that pair alone. Another component is correct verbalizations for the second pair during trials for that pair and the first pair. The final component is correct verbalizations for the third pair during subsequent trials under $\mathrm{W}$ presentation. These components yield values for correct responses for all six photographs that are comparable to those for $\mathrm{P}$ and $\mathrm{W}$ presentation.

$\mathrm{P}, \mathrm{CP}$, or $\mathrm{W}$ presentation made a difference only for breed name $[F(2,24)=4.42, p<.05]$. Correct names were in the order $\mathrm{P}>\mathrm{CP}>\mathrm{W}$. Except for a difference between experimenters for $\mathrm{CC}[\mathrm{F}(1,24)=7.72, \mathrm{p}<.01]$, none of the Fs for gender or experimenter alone or in interaction with each other or with presentation was at $\mathrm{p}<.05$.

All four $\mathrm{Fs}(3,72)$ for trials were at $\mathrm{p}<.01$; they ranged from 5.12 to 23.19 . For names and $C C$, the interaction $\mathrm{Fs}(6,72)$ for presentation and trials were 3.18 and 4.16 , respectively (both at $p<.01$ ). Both interactions reflected faster increases for names and $\mathrm{CC}$ in the order $\mathrm{P}>\mathrm{CP}>\mathrm{W}$.

\section{Acquisition: W}

For the last trial under $\mathrm{P}, \mathrm{CP}$, or $\mathrm{W}$ presentation and the first trial under $W$ presentation, the percentages of correct breed names were 44 and 11, 25 and 19, and 10 and 12 for initial $\mathrm{P}, \mathrm{CP}$, or $\mathrm{W}$ presentation, respectively. The corresponding percentages for $\mathrm{CC}$ were 71 and 54, 62 and 46, and 51 and 50; those for CL were 93 and 85,86 and 82 , and 82 and 76; and those for EC were 90 and 82,85 and 68 , and 79 and 78 . The modal pattern of decreases was $\mathrm{P}>\mathrm{CP}>\mathrm{W}$ with inversions under $\mathrm{CP}$ and $\mathrm{W}$ presentation for $\mathrm{CL}$ and under $\mathrm{P}$ and $\mathrm{CP}$ presentation for EC. Only the differences among decreases in names were large enough to yield an interaction of $\mathrm{P}, \mathrm{CP}$, or $\mathrm{W}$ presentation and last-first trial $[F(2,24)=12.09, p<.01]$.

Across trials, none of the Fs for names, $\mathrm{CC}, \mathrm{CL}$, or EC for initial $\mathrm{P}, \mathrm{CP}$, or $\mathrm{W}$ presentation was at $\mathrm{p}<.05$ for initial presentation alone or in interaction with gender or experimenter. Names, CC, and EC increased over trials with respective $\mathrm{Fs}(3,72)$ of $10.64(p<.01)$, $6.12(p<.01)$, and $3.90(p<.05)$. Trials entered four interactions for which the Fs were at $p<.05$. These Fs were ignored because they were not consistent among names, CC, CL, or EC, or among combinations of trials with one or more among initial presentation, gender, and experimenter.

\section{Transfer: $W$}

For the last trial under $\mathrm{W}$ presentation and the first test trial with photographs omitted, the percentages for CC were 69 and 15, 49 and 21, and 71 and 21 for initial $\mathrm{P}, \mathrm{CP}$, and $\mathrm{W}$ presentation, respectively. The corresponding percentages for $\mathrm{CL}$ were 92 and 32 , 89 and 64, and 85 and 67; and those for EC were 86 and 33,81 and 31 , and 85 and 44 . The modal pattern of decreases was $\mathrm{P}>\mathrm{CP}>\mathrm{W}$; there was an inversion for $\mathrm{CP}$ and $\mathrm{W}$ presentation for CC. Only the differences in decreases for $\mathrm{CC}$ were large enough to yield an interaction of initial presentation and last $\mathrm{W}$ presentation/ first test trial $[F(2,24)=7.04, p<.01]$.

Across trials, the percentages for $\mathrm{CL}$ were $\mathrm{W}>\mathrm{CP}>\mathrm{P} \quad[\mathrm{F}(2,24)=3.88, \mathrm{p}<.05]$. The $\mathrm{Fs}$ for $\mathrm{CC}$ and EC did not reach values at $\mathrm{p}<.05$. None of the Fs for trials alone and only two of the Fs for trials in interaction with one or more among initial presentation, gender, or experimenter were at $p<.05$. The percentage for CC for males was higher than that for females $[F(1,24)=7.41, p<.01]$, which also held for EC $[F(1,24)=4.68, p<.05]$.

\section{DISCUSSION}

\section{Initial, Acquired, and Transferred Verbalizations}

Initial. Across later experience with $\mathrm{P}, \mathrm{CP}$, or $\mathrm{W}$ presentation, the children verbalized correct values of CC and EC on slightly more than $25 \%$ of their opportunities to do so. About $60 \%$ of their verbalizations of $\mathrm{CL}$ were correct. They had some, but not extensive, initial, correct, verbalized knowledge about the cats they saw.

Acquired. Across initial $\mathrm{P}, \mathrm{CP}$, or $\mathrm{W}$ presentation, by the last trial under $W$ presentation, about $30 \%$ of breed names were verbalized correctly. This slow strengthening is consistent with expectations for young children with unfamiliar polysyllabic responses. By the last trial, correct verbalizations of CC, EC, and CL had reached $63 \%, 84 \%$, and $89 \%$, respectively. These responses were generally shorter; for $\mathrm{CL}$, they were limited to a small set of two, presumably familiar responses.

Contrary to expectations based on Postman and Goggin's (1966) Experiment 2, initial strengthening under CP presentation did not occasion more correct names or correct verbalizations of $\mathrm{CC}, \mathrm{CL}$, and $\mathrm{EC}$ than initial strengthening under $\mathrm{P}$ or $\mathrm{W}$ presentation. None of the differences between their experiment and the present experiment in subjects, stimuli, stimulusresponse relationships, or other conditions is an obvious source of this disagreement. The essential equality of initial $P$ or $W$ presentation is consistent with Postman and Goggin's results and with those described by Goss and Nodine (1965, pp. 294-304).

Transferred. When the photographs were omitted, and breed names substituted for stimuli, percentages of correct CC, CL, and EC responses decreased precipitously and did not recover through two further study-test trials. Some transfer occurred but it was small. The strengthening of correct breed names undoubtedly required their verbalization by the experimenter. Conceivably, just seeing the pictures or seeing them under 
instructions to verbalize $\mathrm{CC}, \mathrm{CL}$, and EC might have strengthened these verbalizations. Complementary data with a smaller number of children of lower and more heterogeneous ages indicate that these responses are not strengthened by such exposure and verbalizations.

\section{Fact Matrices Beyond and in the Laboratory}

Parents or their surrogates may ask a child or children to, in varying degrees, note and verbalize the class name for one or more exemplars of a class of objects, to verbalize the names of subclasses of exemplars, and to verbalize some of the attributes and values of attributes of exemplars. When a child or children fail to do so, parents or their surrogates may provide these names, attributes, and values. Repetition of these verbalizations by the child or children may be encouraged. Such repetition assures both an active learner and an opportunity for correction of incorrect verbalizations. Subsequently, mastery of matrices may be tested by presentation of names of subclasses alone as stimuli for verbalization of values of attributes of exemplars, or the converse.

The conditions of initial assessment, of strengthening under initial $\mathrm{P}, \mathrm{CP}$, or $\mathrm{W}$ presentations and then under $\mathrm{W}$ presentations, and of transfer used here, in a quasilaboratory context in a preschool, approximate the conditions presumed to occur in some contexts beyond the laboratory. In general, presentations of stimuli in a laboratory or quasilaboratory context may be more systematic than presentations of those stimuli in contexts beyond the laboratory. However, programs of "intellectual enrichment" in contexts beyond the laboratory may also involve systematic presentation of stimuli including cued correction of incorrect verbalizations.

The initial $\mathrm{P}, \mathrm{CP}$, or $\mathrm{W}$ presentation used here represents a reasonably wide range of variations in presentation of rows of fact matrices that are set up like Table 1 . Other variations in numbers of rows for $\mathrm{P}, \mathrm{CP}$, or $\mathrm{W}$ presentation, more trials under these presentations, or specification of parts by cuts through columns might yield faster strengthening and more transfer under $\mathrm{CP}$ than under $\mathrm{P}$ or $\mathrm{W}$ presentation. At present, however, the generalization that might be extended to contexts beyond the laboratory is that initial permutations of $\mathrm{P}, \mathrm{CP}$, or $\mathrm{W}$ presentation within part-whole manipulation are likely to make no difference in acquisition and transfer with those many fact matrices whose stimulus and response elements and relationships resemble those of the cat matrix used here. Parents and teachers can probably present these elements and relationships as convenient for them and the child. They do not need to strive to discover and to use some optimum variation on $\mathrm{P}, \mathrm{CP}$, or $\mathrm{W}$ presentation.

\section{REFERENCES}

Goss, A. E. Paired associates and connected discourse in the acquisition of knowledge. In E. Z. Rothkopf \& P. E. Johnson (Eds.), Verbal learning research and the technology of written instruction. New York: Teachers' College, 1971.

Goss, A. E., \& Nodine, C. F. Paired associates learning. New York: Academic Press, 1965.

Musgrave, B. S., \& Cohen, J. C. Relationships between prose and list learning. In E. Z. Rothkopf \& P. E. Johnson (Eds.), Verbal learning research and the technology of written instruction. New York: Teachers' College, 1971.

Postman, L., \& Goggin, J. Whole versus part learning of paired associates lists. Journal of Experimental Psychology, 1966, 71, 867-877.

WARNER, M. Cats of the world. New York: Bantam, 1976.

(Received for publication May 13, 1979.) 